\title{
Structure and Magnetic Properties of Nanocrystalline Fe-Mo Alloys Prepared by Mechanosynthesis
}

\author{
M. Karolus ${ }^{a, *}$, E. Jartych ${ }^{b}$ and D. OleszaK ${ }^{c}$
}

${ }^{a}$ Institute of Physics and Chemistry of Metals, University of Silesia

Bankowa 12, 40-007 Katowice, Poland

${ }^{b}$ Department of Experimental Physics, Institute of Physics

Technical University of Lublin, Nadbystrzycka 38, 20-618 Lublin, Poland

${ }^{c}$ Warsaw University of Technology

Department of Materials Science and Engineering

Wołoska 141, 02-507 Warsaw, Poland

\begin{abstract}
Nanocrystalline samples of $\mathrm{Fe}_{80} \mathrm{Mo}_{20}$ and $\mathrm{Fe}_{50} \mathrm{Mo}_{50}$ alloys were prepared by the mechanical milling method. The structure, lattice parameters, and crystallite size were determined by the X-ray diffraction. The magnetic properties of the milled products were determined by the Mössbauer spectroscopy. It was observed that in the case of the $\mathrm{Fe}_{80} \mathrm{Mo}_{20}$ alloy a solid solution of Mo in Fe was formed with the lattice parameters of Fe increasing from $0.28659 \mathrm{~nm}$ to $0.29240 \mathrm{~nm}$ and the crystallite size decreasing from $250 \mathrm{~nm}$ to $20 \mathrm{~nm}$. In the case of the $\mathrm{Fe}_{50} \mathrm{M}_{50}$ alloy there were no clear changes in values of the lattice parameters of $\mathrm{Fe}$ and Mo during the milling process, but the crystallite size decreased from $200 \mathrm{~nm}$ to $15 \mathrm{~nm}$. Mössbauer spectra revealed different magnetic phases in the mechanosynthesized Fe-Mo samples. In the case of the $\mathrm{Fe}_{80} \mathrm{Mo}_{20}$ alloy, the spectrum for the milled mixture indicated the formation of a solid solution. In contrast, for the $\mathrm{Fe}_{50} \mathrm{Mo}_{50}$ the spectrum indicated the disappearance of the ferromagnetic phase.
\end{abstract}

PACS numbers: 61.10.Eq, 07.85.Jy, 81.07.Bc, 81.07.Wx, 61.18.Fs, 87.64.Pj

\section{Introduction}

In the last few years, different types of nanocrystalline materials have been the subject of numerous papers. Mechanical alloying is one of the methods that

*corresponding author; e-mail: karolus@us.edu.pl 
allows the formation of a nanocrystalline structure. In the case of the materials obtained by the mechanical alloying the processes of the formation of the supersaturated solid solutions can also be studied as well as the process of amorphization. The influence of mechanical alloying and milling on some magnetic properties of alloys has also been investigated. Such nanocrystalline materials exhibit magnetization, coercivity, and hyperfine magnetic fields different from those for bulk or coarse-grained materials.

The aim of this paper was to investigate the process of the formation of a solid solution of molybdenum in iron during mechanical alloying of mixtures of $\mathrm{Fe}$ and Mo powders having overall compositions $\mathrm{Fe}_{80} \mathrm{MO}_{20}$ and $\mathrm{Fe}_{50} \mathrm{Mo}_{50}$. Some magnetic properties of these alloys were also determined.

\section{Experimental}

Powders of $\mathrm{Fe}$ and Mo, with purities better than $99.9 \%$ and particle sizes below 40 and 10 microns, respectively, were mixed together to obtain $\mathrm{Fe}_{80} \mathrm{Mo}_{20}$ and $\mathrm{Fe}_{50} \mathrm{M}_{50}$ compositions (at.\%). Mechanical milling of the powders was performed in a Fritsch Pulverisette P5 planetary ball mill. Stainless steel vials and balls were used. The ball-to-powder weight ratio was 10:1 and the total mass of the milled powders was $10 \mathrm{~g}$. The milling processes were carried out at room temperature with a milling speed of $250 \mathrm{rpm}$. All powder handling (mixing the powders before milling and withdrawing small amounts of powders for studies after various milling times) was performed in a glove bag under an argon atmosphere.

A Philips Diffractometer (PW 1130 model) with copper radiation ( $K_{\alpha}=$ $1.54178 \AA$ ) and having a graphite monochromator in the diffracted beam was used for X-ray diffraction (XRD) studies. The range of measurements was from 30 to $120^{\circ} 2 \theta$ in steps of $0.05^{\circ}$ for $4 \mathrm{~s}$. For lattice parameters determination the additional scans were performed with $2 \theta$ steps of $0.01^{\circ}$ for $40 \mathrm{~s}$. X-ray diffraction measurements were performed at various stages of milling of the mixed powders. The lattice parameters were calculated using the procedure of whole-powder-pattern fitting without reference to a structural model proposed by Toraya [1]. For calculations of the crystallite size $D$, the Williamson-Hall approach was adopted [2]. For structure determinations on nanocrystalline samples the Rietveld refinement was used [3].

Mössbauer spectroscopy was used to obtain information about the hyperfine interactions, e.g. local interactions between the nuclear probes ${ }^{57} \mathrm{Fe}$ contained in the mixtures and the nearest environment of the probes. This experimental technique allows not only monitoring of the progress of solid-state reactions of mixed elemental powders but also determination of the magnetic properties of the phases formed during milling. Measurements were carried out at room temperature with standard transmission geometry, using a ${ }^{57}$ Co source in a rhodium matrix (activity $50 \mathrm{mCi}$. 


\section{Discussion}

The obtained X-ray diffraction patterns allowed studying the process of the alloy formation. Figure 1 presents the X-ray diffraction spectra obtained for both alloys after the different times of milling. In case of $\mathrm{Fe}_{80} \mathrm{Mo}_{20}$ alloy it was observed that the intensity of the characteristic Mo lines gradually decreased with no change in $2 \theta$ positions and the characteristic Fe lines slightly changed $2 \theta$ positions (in the direction of low angles). The change of the lattice parameter versus milling time is presented in Fig. 2a. The $a$ value of Fe increased from $a=0.28659 \mathrm{~nm}$ to $a=0.29240 \mathrm{~nm}$ and the $a$ value of Mo was almost constant $(a=0.31470 \div$ $0.31452 \mathrm{~nm}$ ). A distinct change of slope is visible after about 10 hours of milling. For structure determination the Rietveld refinement was used. The significant increase in the lattice parameter values after 10 hours indicated that the formation of a bcc structured solid solution of Mo in Fe was beginning. However, even after 80 hours of milling the characteristic lines of Mo are still visible. The changes of the iron lattice parameter, after the rapid increase between 10 and $40 \mathrm{~h}$, slowly stabilized after $60 \mathrm{~h}$ of milling. From the results described above, the creation of the supersaturated solid solution of molybdenum in iron can be concluded. The equilibrium solubility limit of $\mathrm{Mo}$ in $\mathrm{Fe}$ is about 2.5 at.\% at $700^{\circ} \mathrm{C}$. Moreover, it was noticed that the crystallite size $D$ decreased with increasing time of milling from $250 \mathrm{~nm}$ to $20 \mathrm{~nm}$.

In case of $\mathrm{Fe}_{50} \mathrm{Mo50}_{50}$ alloy it was observed that the characteristic $\mathrm{Fe}$ and Mo lines, in general, underwent no changes in intensities and $2 \theta$ positions. The values of the lattice parameters of $\mathrm{Fe}$ and Mo are presented in Fig. 2b and show that $a_{\mathrm{Fe}}=0.28659$ to $0.28695 \mathrm{~nm}$ and $a_{\mathrm{Mo}}=0.3147$ to $0.3145 \mathrm{~nm}$. However, the crystallite size changed with milling time in the range from $200 \mathrm{~nm}$ to $15 \mathrm{~nm}$. The results of Rietveld refinement confirmed the observation that the process of milling did not lead to the creation of solid solution. However, the results obtained are different from data presented by Young et al. [4] in which the formation of an amorphous phase $(\mathrm{Fe}-\mathrm{Mo})$ after only 24 hours of milling was observed.

For both compositions, the Mössbauer spectra of the samples milled for 2 and $5 \mathrm{~h}$ are characteristic of $\alpha$-iron, e.g., a sextet with a hyperfine magnetic field of $B_{\mathrm{hf}}=33.0(1) \mathrm{T}$ and an isomer shift (relative to $\alpha$-iron) of $\delta=0.01(1) \mathrm{mm} \mathrm{s}^{-1}$ could be fitted to the experimental spectrum. After $10 \mathrm{~h}$ of milling the shapes of the spectra changed, namely an additional line appeared in the centre of the spectrum and a broadening of the spectral lines in relation to $\alpha$-iron lines was observed.

In the case of the spectra for $\mathrm{Fe}_{80} \mathrm{Mo}_{20}$ (Fig. 3a) those for the mixtures milled for 22, 40,60 and 80 hours show the process of alloy formation. The spectrum of the sample milled for 80 hours was fitted numerically by a hyperfine magnetic field distribution [5]. The average value of the hyperfine magnetic field is about $24.6 \mathrm{~T}$. However, the hyperfine magnetic field of $33 \mathrm{~T}$ characteristic of iron also exists in the distribution, which indicates the presence of some free iron, unreacted with Mo. 

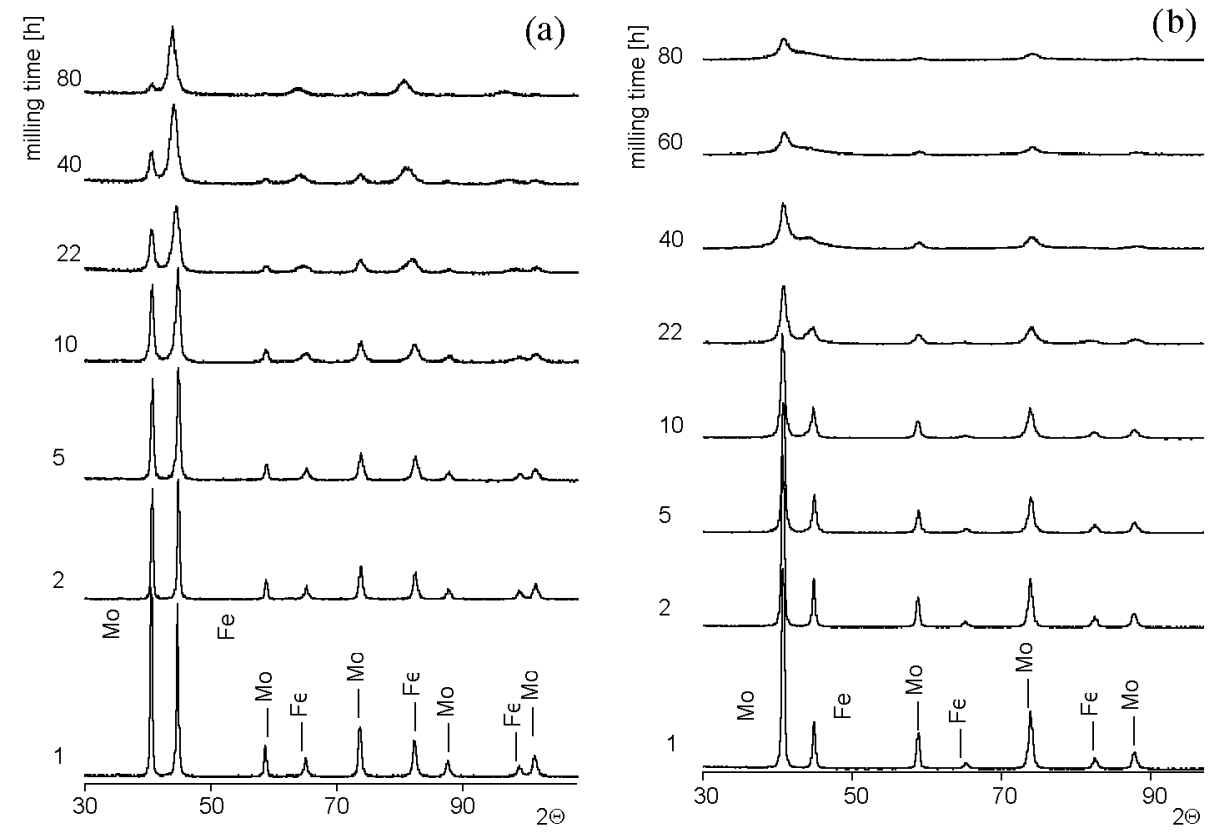

Fig. 1. X-ray diffraction patterns of alloys as a function of milling time: (a) $\mathrm{Fe}_{80} \mathrm{Mo}_{20}$ alloy, (b) Feso Mo50 alloy.
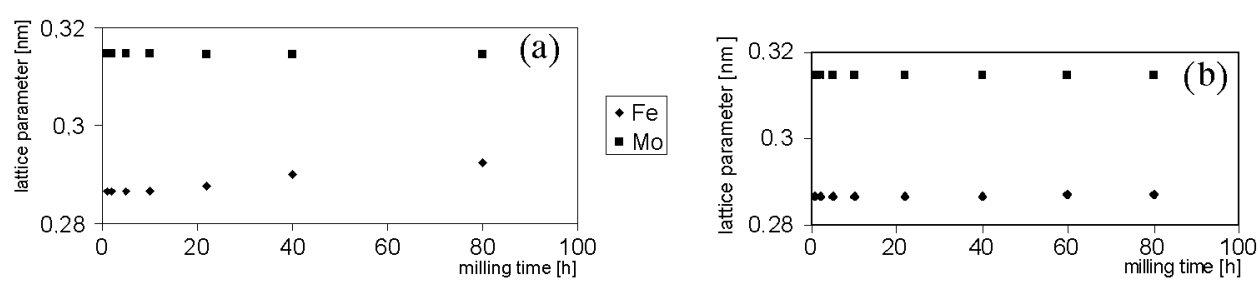

Fig. 2. Lattice parameters of alloys versus milling time: (a) $\mathrm{Fe}_{80} \mathrm{Mo}_{20}$ alloy, (b) $\mathrm{Fe}_{50} \mathrm{Mo}_{50}$ alloy.

Hence, ferromagnetic disordered solid solution was formed during the mechanical alloying process of the $\mathrm{Fe}_{80} \mathrm{Mo}_{20}$. Moreover, for the sample milled for 80 hours a trace of paramagnetic arrangement was found.

In the case of the $\mathrm{Fe}_{50} \mathrm{Mo}_{50}$ composition (Fig. 3b) the spectrum of the mixture milled for 22 hours still consists of a sextet and a doublet. The first trace of paramagnetic arrangement is visible for $10 \mathrm{~h}$ of milling. After 40 hours the ferromagnetic arrangement completely disappears from the mixture. It means that the transition from the ferromagnetic to paramagnetic arrangement is observed. The spectra for the samples milled for 40,60 and $80 \mathrm{~h}$ were fitted numerically by a doublet distribution [5]. The average value of the quadrupole splitting was about $0.20 \mathrm{~mm} \mathrm{~s}^{-1}$. The XRD analysis showed no trace of the amorphization of Fe ${ }_{50} \mathrm{Mos}_{50}$ composition in our mechanical alloying process. Hence, the transition from a fer- 

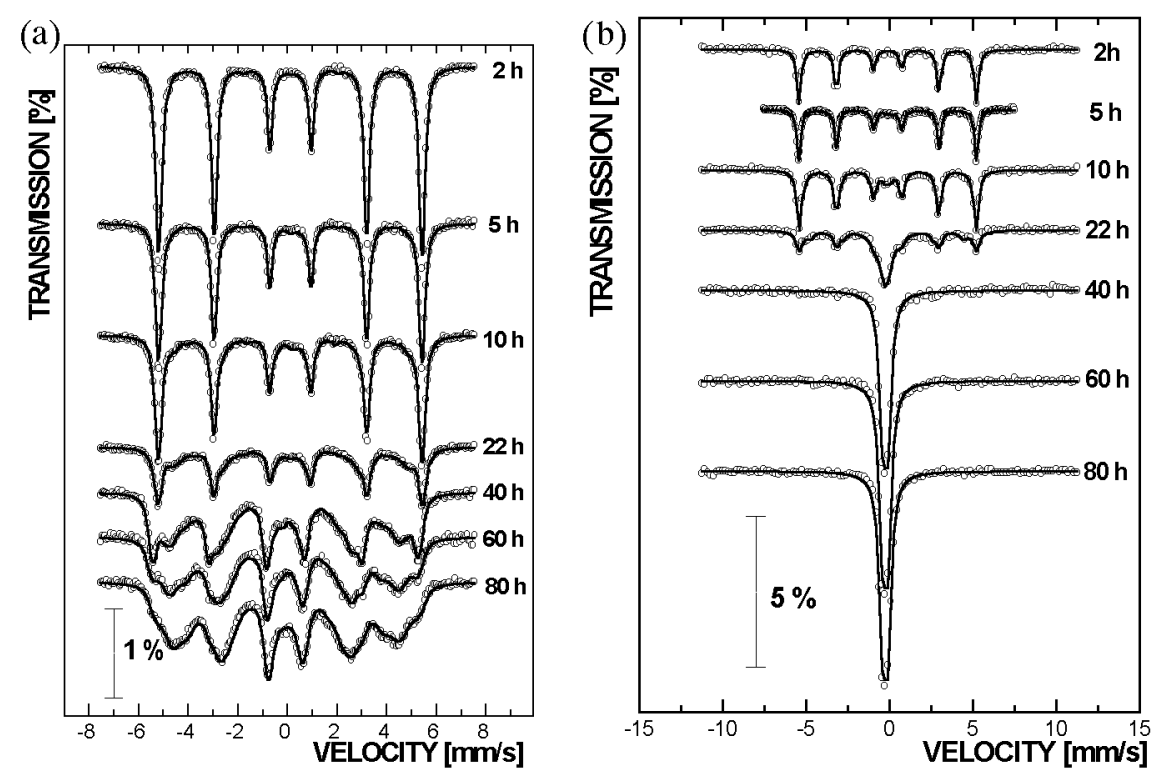

Fig. 3. Room-temperature Mössbauer spectra of the mechanosynthesized alloys collected after various times of milling in high-energy ball mill: (a) $\mathrm{Fe}_{80} \mathrm{Mo}_{20}$ alloy, (b) $\mathrm{Fe}_{50} \mathrm{Mo}_{50}$ alloy.

romagnetic to a paramagnetic arrangement in the milled $\mathrm{Fe}_{50} \mathrm{Mo}_{50}$, indicated by the Mössbauer data cannot be explained on the basis of an amorphization process. A possible interpretation of this transition is a superparamagnetic phenomenon, however this problem will be a subject of further investigations.

\section{Summary}

X-ray diffraction and Mössbauer spectroscopy are complementary techniques in the study of mechanosynthesized materials. The process of mechanical alloying by milling of the iron and molybdenum powders ( 80 and 20 at.\%) resulted in the formation of a solid solution of molybdenum in iron. The alloying process began after 10 hours of milling. The bcc solid solution had a lattice parameter $a=0.2924 \mathrm{~nm}$ and a crystallite size $D$ was $20 \mathrm{~nm}$ after $80 \mathrm{~h}$ of milling. However, in the case of $\mathrm{Fe}_{50} \mathrm{Mo}_{50}$ the milling did not lead to the formation of solid solution. The lattice parameter of iron remained almost constant at $0.28659 \div 0.28695 \mathrm{~nm}$ and a crystallite size $D$ was $15 \mathrm{~nm}$ after $80 \mathrm{~h}$ of milling. Basing on the fact that after $80 \mathrm{~h}$ of milling the characteristic Mo lines are also visible and that the trace of paramagnetic arrangement was noticed in the Mössbauer spectrum, it was concluded that the solid solution of iron in molybdenum is formed too. 
In the case of $\mathrm{Fe}_{50} \mathrm{Mo}_{50}$ the mechanical alloying did not lead to the formation of solid solution molybdenum in iron but reassuming the results of Mössbauer studies it was concluded that the solid solution of iron in molybdenum is formed. The process began after $10 \mathrm{~h}$ of milling and finished after $40 \mathrm{~h}$. Mössbauer spectra revealed different magnetic phases in the mechanosynthesized Fe-Mo. In the case of the $\mathrm{Fe}_{80} \mathrm{Mo}_{20}$ alloy, a ferromagnetic phase was dominant in the final milled product. For $\mathrm{Fe}_{50} \mathrm{Mo}_{50}$ a transition from a two-phase mixture i.e. ferro-paramagnetic, to a single-paramagnetic phase was observed after $40 \mathrm{~h}$ of milling.

\section{References}

[1] H. Toraya, J. Appl. Crystallogr. 19, 440 (1986).

[2] G.K. Williamson, W.H. Hall, Acta Metallogr. 1, 22 (1953).

[3] H. Rietveld, J. Appl. Crystallogr. 2, 65 (1969).

[4] E. Young, C.N.J. Wagner, M.S. Boldrick, Key Eng. Mater. 81-83, 663 (1993).

[5] J. Hesse, A. Rübartsch, J. Phys. E, Sci. Instrum. 7, 526 (1974). 